\title{
Transparent reporting of a multivariable prediction model for individual prognosis or diagnosis (TRIPOD): the TRIPOD Statement
}

\author{
Gary S Collins ${ }^{1 *}$, Johannes B Reitsma ${ }^{2}$, Douglas G Altman ${ }^{1}$ and Karel GM Moons ${ }^{2}$
}

\begin{abstract}
Prediction models are developed to aid health care providers in estimating the probability or risk that a specific disease or condition is present (diagnostic models) or that a specific event will occur in the future (prognostic models), to inform their decision making. However, the overwhelming evidence shows that the quality of reporting of prediction model studies is poor. Only with full and clear reporting of information on all aspects of a prediction model can risk of bias and potential usefulness of prediction models be adequately assessed. The Transparent Reporting of a multivariable prediction model for Individual Prognosis Or Diagnosis (TRIPOD) Initiative developed a set of recommendations for the reporting of studies developing, validating, or updating a prediction model, whether for diagnostic or prognostic purposes. This article describes how the TRIPOD Statement was developed. An extensive list of items based on a review of the literature was created, which was reduced after a Web-based survey and revised during a 3-day meeting in June 2011 with methodologists, health care professionals, and journal editors. The list was refined during several meetings of the steering group and in e-mail discussions with the wider group of TRIPOD contributors. The resulting TRIPOD Statement is a checklist of 22 items, deemed essential for transparent reporting of a prediction model study. The TRIPOD Statement aims to improve the transparency of the reporting of a prediction model study regardless of the study methods used. The TRIPOD Statement is best used in conjunction with the TRIPOD explanation and elaboration document. To aid the editorial process and readers of prediction model studies, it is recommended that authors include a completed checklist in their submission (also available at www.tripod-statement.org).

Editors' note: In order to encourage dissemination of the TRIPOD Statement, this article is freely accessible on the Annals of Internal Medicine Web site (www.annals.org) and will be also published in BJOG, British Journal of Cancer, British Journal of Surgery, BMC Medicine, British Medical Journal, Circulation, Diabetic Medicine, European Journal of Clinical Investigation, European Urology, and Journal of Clinical Epidemiology. The authors jointly hold the copyright of this article. An accompanying Explanation and Elaboration article is freely available only on www.annals.org; Annals of Internal Medicine holds copyright for that article.
\end{abstract}

Keywords: Prediction models, Prognostic, Diagnostic, Model development, Validation, Transparency, Reporting

\section{Background}

In medicine, patients with their care providers are confronted with making numerous decisions on the basis of an estimated risk or probability that a specific disease or condition is present (diagnostic setting) or a specific event will occur in the future (prognostic setting) (Figure 1). In

\footnotetext{
*Correspondence: gary.collins@csm.ox.ac.uk

'Nuffield Department of Orthopaedics, Rheumatology and Musculoskeletal Sciences, Botnar Research Centre, Centre for Statistics in Medicine, University of Oxford, Oxford OX3 7LD, UK

Full list of author information is available at the end of the article
}

the diagnostic setting, the probability that a particular disease is present can be used, for example, to inform the referral of patients for further testing, initiate treatment directly, or reassure patients that a serious cause for their symptoms is unlikely. In the prognostic setting, predictions can be used for planning lifestyle or therapeutic decisions based on the risk for developing a particular outcome or state of health within a specific period [1,2]. Such estimates of risk can also be used to risk-stratify participants in therapeutic clinical trials $[3,4]$.

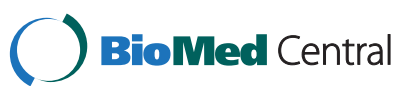




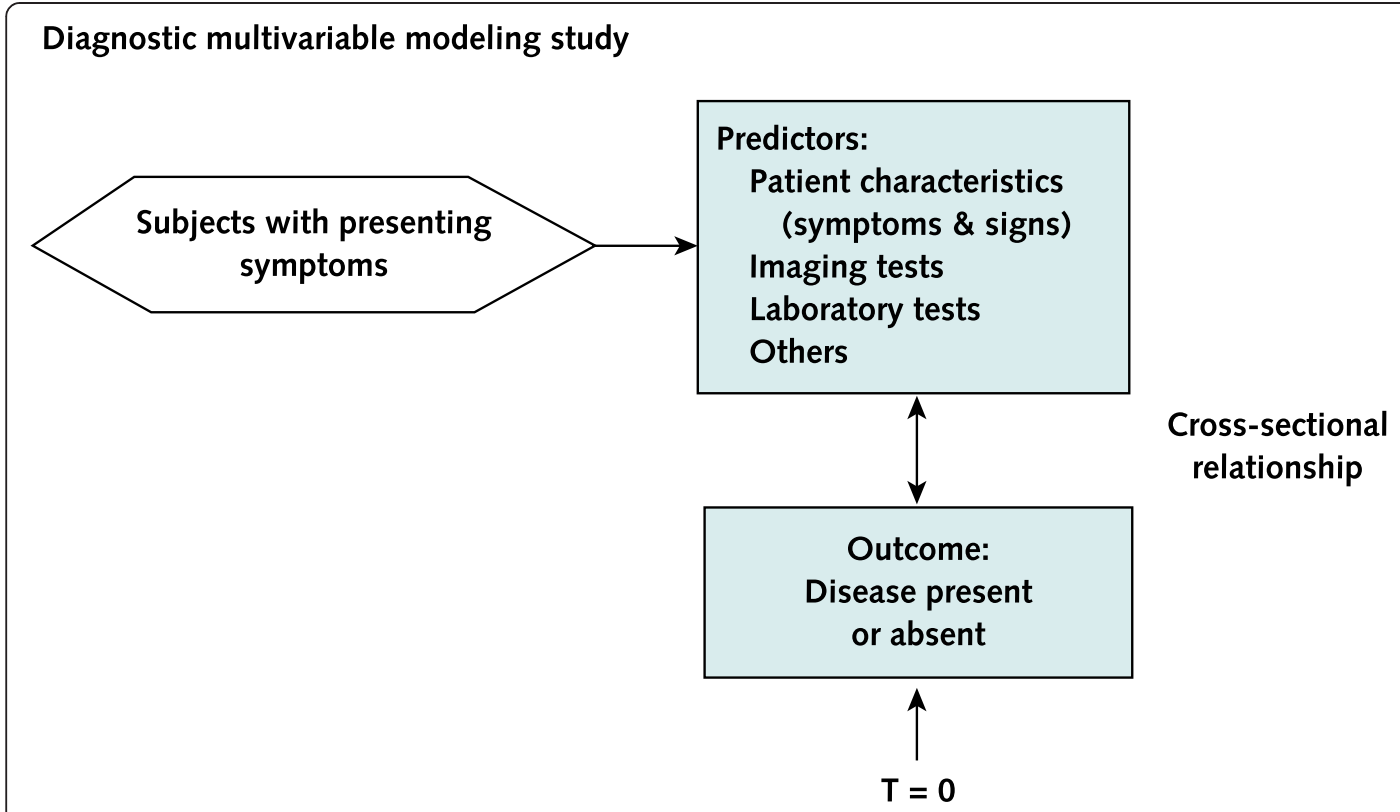

Prognostic multivariable modeling study
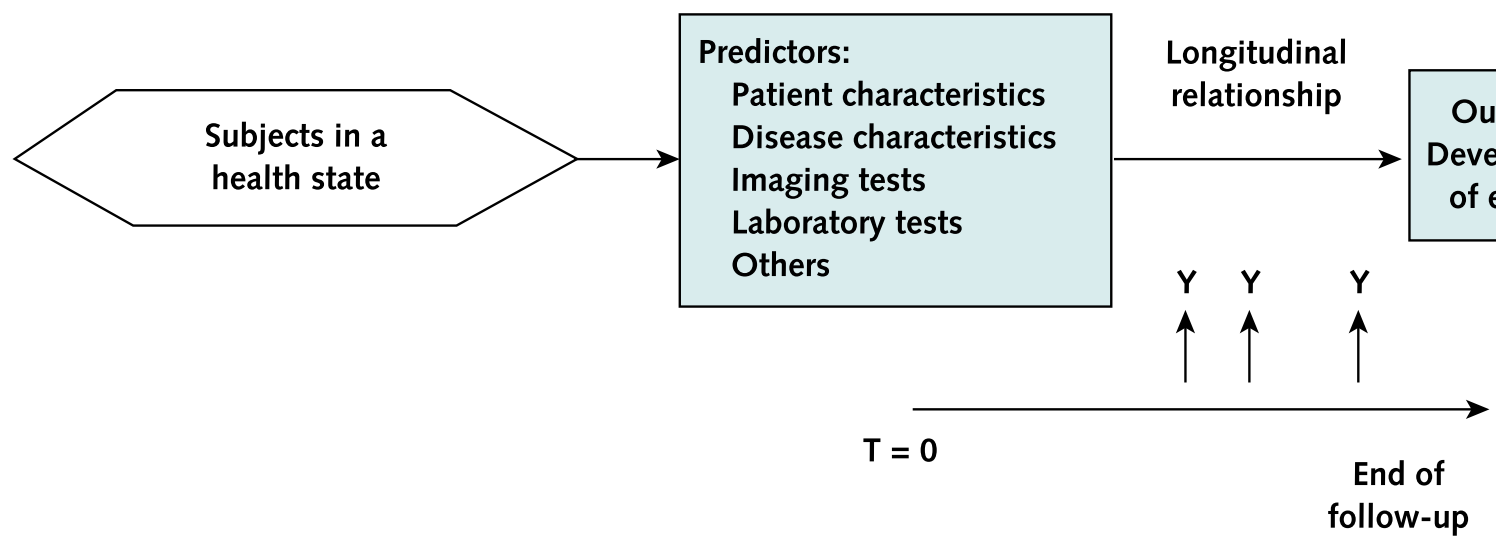

Figure 1 Schematic representation of diagnostic and prognostic prediction modeling studies. The nature of the prediction in diagnosis is estimating the probability that a specific outcome or disease is present (or absent) within an individual, at this point in time- that is, the moment of prediction $(T=0)$. In prognosis, the prediction is about whether an individual will experience a specific event or outcome within a certain time period. In other words, in diagnostic prediction the interest is in principle a cross-sectional relationship, whereas prognostic prediction involves a longitudinal relationship. Nevertheless, in diagnostic modeling studies, for logistical reasons, a time window between predictor (index test) measurement and the reference standard is often necessary. Ideally, this interval should be as short as possible and without starting any treatment within this period.

In both the diagnostic and prognostic setting, estimates of probabilities are rarely based on a single predictor [5]. Doctors naturally integrate several patient characteristics and symptoms (predictors, test results) to make a prediction (see Figure 2 for differences in common terminology between diagnostic and prognostic studies). Prediction is therefore inherently multivariable. Prediction models (also commonly called "prognostic models," "risk scores," or "prediction rules" [6]) are tools that combine multiple predictors by assigning relative weights to each predictor to obtain a risk or probability $[1,2]$. Well-known prediction models include the
Framingham Risk Score [7], Ottawa Ankle Rules [8], EuroScore [9], Nottingham Prognostic Index [10], and the Simplified Acute Physiology Score [11].

\section{Prediction model studies}

Prediction model studies can be broadly categorized as model development [12], model validation (with or without updating) [13] or a combination of both (Figure 3). Model development studies aim to derive a prediction model by selecting the relevant predictors and combining them statistically into a multivariable model. Logistic and Cox regression are most 


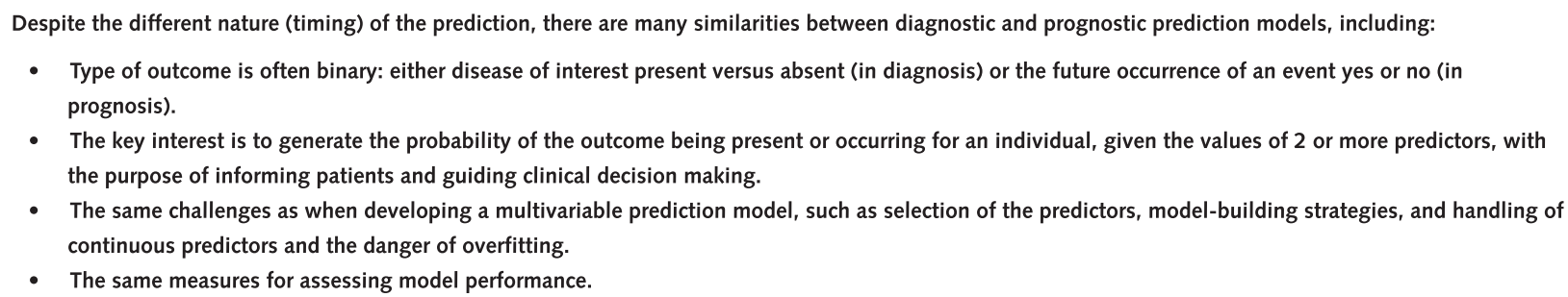

Different terms for similar features between diagnostic and prognostic modeling studies are summarized below.

Diagnostic Prediction Modeling Study

Diagnostic tests or index tests

Reference standard and disease verification

Partial verification
Explanatory variables, predictors, covariates ( $X$ variables)

Outcome (Y variable)

Event definition and event measurement

Loss to follow-up and censoring

Figure 2 Similarities and differences between diagnostic and prognostic prediction models.

frequently used for short-term (for example, disease absent vs. present, 30-day mortality) and long-term (for example, 10-year risk) outcomes, respectively [12-17]. Studies may also focus on quantifying the incremental or added predictive value of a specific predictor (for example, newly discovered) to a prediction model [18].

Quantifying the predictive ability of a model on the same data from which the model was developed (often referred to as apparent performance) will tend to give an optimistic estimate of performance, owing to overfitting (too few outcome events relative to the number of candidate predictors) and the use of predictor selection strategies [19]. Studies developing new prediction models should therefore always include some form of internal validation to quantify any optimism in the predictive performance (for example, calibration and discrimination) of the developed model. Internal validation techniques use only the original study sample and include such methods as bootstrapping or cross-validation. Internal validation is a necessary part of model development [2]. Overfitting, optimism, and miscalibration may also be addressed and accounted for during the model development by applying shrinkage (for example, heuristic or based on bootstrapping techniques) or penalization procedures (for example, ridge regression or lasso) [20].

After developing a prediction model, it is strongly recommended to evaluate the performance of the model in other participant data than was used for the model development. Such external validation requires that for each individual in the new data set, outcome predictions are made using the original model (that is, the published regression formula) and compared with the observed outcomes [13,14]. External validation may use participant data collected by the same investigators, typically using the same predictor and outcome definitions and measurements, but sampled from a later period (temporal or narrow validation); by other investigators in another hospital or country, sometimes using different definitions and measurements (geographic or broad validation); in similar participants but from an intentionally different setting (for example, model developed in secondary care and assessed in similar participants but selected from primary care); or even in other types of participants (for example, model developed in adults and assessed in children, or developed for predicting fatal events and assessed for predicting nonfatal events) $[13,15,17,21,22]$. In case of poor performance, the model can be updated or adjusted on the basis of the validation data set [13].

\section{Reporting of multivariable prediction model studies}

Studies developing or validating a multivariable prediction model share specific challenges for researchers [6]. Several reviews have evaluated the quality of published reports that describe the development or validation prediction models [23-28]. For example, Mallett and colleagues [26] examined 47 reports published in 2005 presenting new prediction models in cancer. Reporting was found to be poor, with insufficient information described in all aspects of model development, from descriptions of patient data to statistical modeling methods. Collins and colleagues [24] evaluated the 


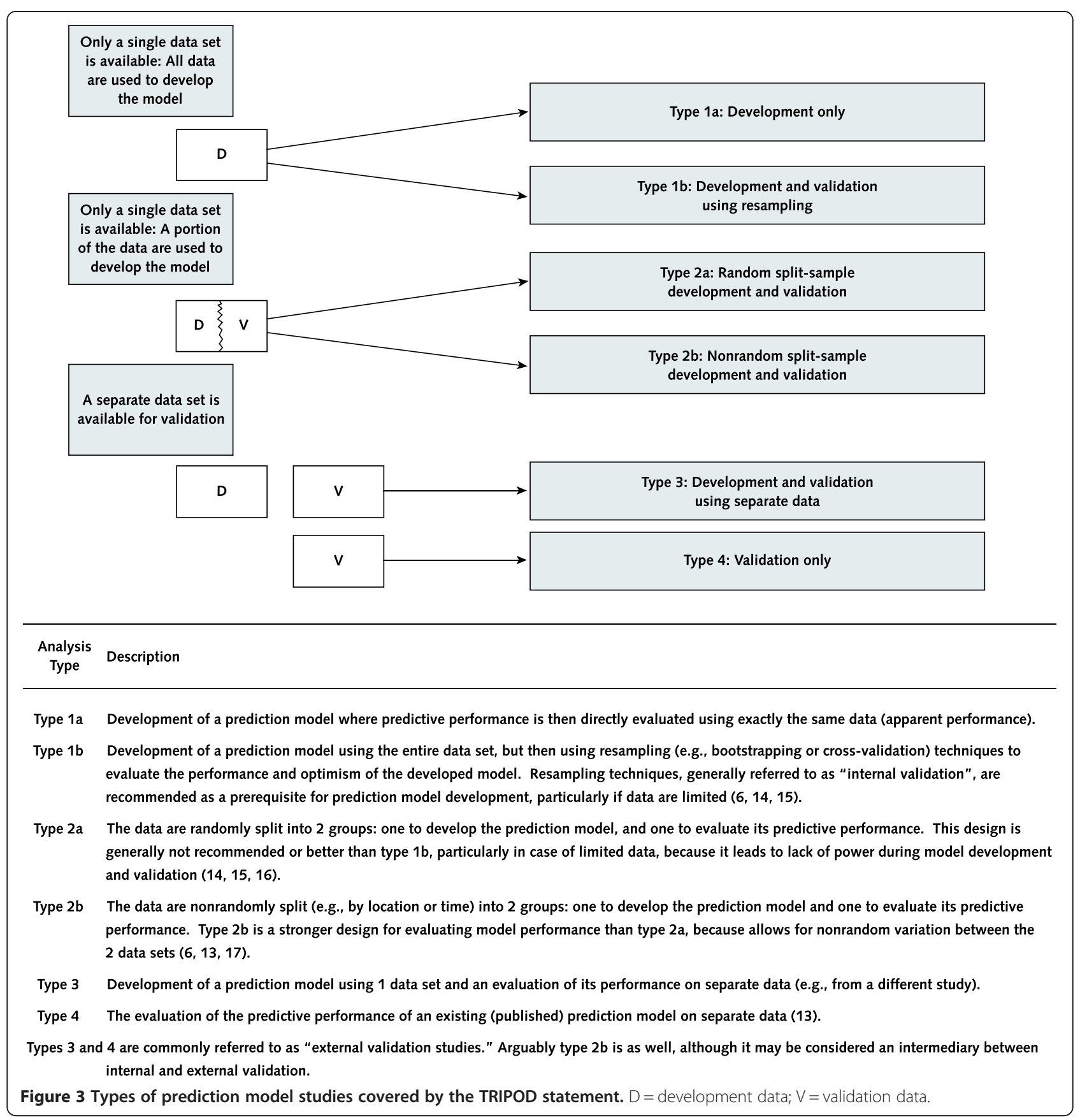

methodological conduct and reporting of 39 reports published before May 2011 describing the development of models to predict prevalent or incident type 2 diabetes. Reporting was also found to be generally poor, with key details on which predictors were examined, the handling and reporting of missing data, and model-building strategy often poorly described. Bouwmeester and colleagues [23] evaluated 71 reports, published in 2008 in 6 high-impact general medical journals, and likewise observed an overwhelmingly poor level of reporting. These and other reviews provide a clear picture that, across different disease areas and different journals, there is a generally poor level of reporting of prediction model studies $[6,2-27,29]$. Furthermore, these reviews have shown that serious deficiencies in the statistical methods, use of small data sets, inappropriate handling of missing data, and lack of validation are common $[6,23-27,29]$. Such deficiencies ultimately lead to prediction models that are not or should not be used. It is therefore not surprising, and fortunate, that very few prediction models, relative to the large number of models published, are widely implemented or used in clinical practice [6]. 
Prediction models in medicine have proliferated in recent years. Health care providers and policy makers are increasingly recommending the use of prediction models within clinical practice guidelines to inform decision making at various stages in the clinical pathway [30,31]. It is a general requirement of reporting of research that other researchers can, if required, replicate all the steps taken and obtain the same results [32]. It is therefore essential that key details of how a prediction model was developed and validated be clearly reported to enable synthesis and critical appraisal of all relevant information [14,33-36].

\section{Reporting guidelines for prediction model studies: the TRIPOD statement}

We describe the development of the TRIPOD (Transparent Reporting of a multivariable prediction model for Individual Prognosis or Diagnosis) Statement, a guideline specifically designed for the reporting of studies developing or validating a multivariable prediction model, whether for diagnostic or prognostic purposes. TRIPOD is not intended for multivariable modeling in etiologic studies or for studies investigating single prognostic factors [37]. Furthermore, TRIPOD is also not intended for impact studies that quantify the impact of using a prediction model on participant or doctors' behavior and management, participant health outcomes, or cost-effectiveness of care, compared with not using the model $[13,38]$.

Reporting guidelines for observational (the STrengthening the Reporting of OBservational studies in Epidemiology [STROBE]) [39], tumor marker (REporting recommendations for tumour MARKer prognostic studies [REMARK]) [37], diagnostic accuracy (STAndards for the Reporting of Diagnostic accuracy studies [STARD]) [40], and genetic risk prediction (Genetic RIsk Prediction Studies [GRIPS]) [41] studies all contain many items that are relevant to studies developing or validating prediction models. However, none of these guidelines are entirely appropriate for prediction model studies. The 2 guidelines most closely related to prediction models are REMARK and GRIPS. However, the focus of the REMARK checklist is primarily on prognostic factors and not prediction models, whereas the GRIPS statement is aimed at risk prediction using genetic risk factors and the specific methodological issues around handling large numbers of genetic variants.

To address a broader range of studies, we developed the TRIPOD guideline: Transparent Reporting of a multivariable prediction model for Individual Prognosis or Diagnosis. TRIPOD explicitly covers the development and validation of prediction models for both diagnosis and prognosis, for all medical domains and all types of predictors. TRIPOD also places much more emphasis on validation studies and the reporting requirements for such studies. The reporting of studies evaluating the incremental value of specific predictors, beyond established predictors or even beyond existing prediction models [18,42], also fits entirely within the remit of TRIPOD (see the accompanying explanation and elaboration document [43]).

\section{Developing the TRIPOD statement}

We convened a 3-day meeting with an international group of prediction model researchers, including statisticians, epidemiologists, methodologists, health care professionals, and journal editors (from Annals of Internal Medicine, BMJ, Journal of Clinical Epidemiology, and PLoS Medicine) to develop recommendations for the TRIPOD Statement.

We followed published guidance for developing reporting guidelines [44] and established a steering committee (Drs. Collins, Reitsma, Altman, and Moons) to organize and coordinate the development of TRIPOD. We conducted a systematic search of MEDLINE, EMBASE, PsychINFO, and Web of Science to identify any published articles making recommendations on reporting of multivariable prediction models (or aspects of developing or validating a prediction model), reviews of published reports of multivariable prediction models that evaluated methodological conduct or reporting and reviews of methodological conduct and reporting of multivariable models in general. From these studies, a list of 129 possible checklist items was generated. The steering committee then merged related items to create a list of 76 candidate items.

Twenty-five experts with a specific interest in prediction models were invited by e-mail to participate in the Web-based survey and to rate the importance of the 76 candidate checklist items. Respondents (24 of 27) included methodologists, health care professionals, and journal editors. (In addition to the 25 meeting participants, the survey was also completed by 2 statistical editors from Annals of Internal Medicine).

The results of the survey were presented at a 3-day meeting in June 2011, in Oxford, United Kingdom; it was attended by 24 of the 25 invited participants (22 of whom had participated in the survey). During the 3-day meeting, each of the 76 candidate checklist items was discussed in turn, and a consensus was reached on whether to retain, merge with another item, or omit the item. Meeting participants were also asked to suggest additional items. After the meeting, the checklist was revised by the steering committee during numerous face-to-face meetings, and circulated to the participants to ensure it reflected the discussions. While making revisions, conscious efforts were made to harmonize our recommendations with other reporting guidelines, and where possible we chose the same or similar wording for items $[37,39,41,45,46]$.

\section{TRIPOD components}

The TRIPOD Statement is a checklist of 22 items that we consider essential for good reporting of studies developing or validating multivariable prediction models (Table 1). 
Table 1 Checklist of items to include when reporting a study developing or validating a multivariable prediction model for diagnosis or prognosis*

\begin{tabular}{llll}
\hline Section/topic Item & Development or validation? & Checklist item & Page
\end{tabular}

Title and abstract

Title

$1 \quad D ; V$

Abstract

\section{Introduction}

Background and objectives

Methods

Source of data

Participants

Outcome

Predictors

Sample size

Missing data

Statistical analysis methods

Risk groups

$11 \quad D ; V$

Development vs. validation

$12 \mathrm{~V}$

Identify the study as developing and/or validating a multivariable prediction model, the target population, and the outcome to be predicted.

Provide a summary of objectives, study design, setting, participants, sample size, predictors, outcome, statistical analysis, results, and conclusions.

Explain the medical context (including whether diagnostic or prognostic) and rationale for developing or validating the multivariable prediction model, including references to existing models.

Specify the objectives, including whether the study describes the development or validation of the model, or both.

Describe the study design or source of data (e.g., randomized trial, cohort, or registry data), separately for the development and validation data sets, if applicable.

Specify the key study dates, including start of accrual; end of accrual; and, if applicable, end of follow-up.

Specify key elements of the study setting (e.g., primary care, secondary care, general population) including number and location of centres.

Describe eligibility criteria for participants.

Give details of treatments received, if relevant.

Clearly define the outcome that is predicted by the prediction model, including how and when assessed.

Report any actions to blind assessment of the outcome to be predicted.

Clearly define all predictors used in developing the multivariable prediction model, including how and when they were measured.

Report any actions to blind assessment of predictors for the outcome and other predictors.

Explain how the study size was arrived at.

Describe how missing data were handled (e.g., complete-case analysis, single imputation, multiple imputation) with details of any imputation method.

Describe how predictors were handled in the analyses.

Specify type of model, all model-building procedures (including any predictor selection), and method for internal validation.

For validation, describe how the predictions were calculated.

Specify all measures used to assess model performance and, if relevant, to compare multiple models.

Describe any model updating (e.g., recalibration) arising from the validation, if done.

Provide details on how risk groups were created, if done.

For validation, identify any differences from the development data in setting, eligibility criteria, outcome, and predictors. 


\section{Table 1 Checklist of items to include when reporting a study developing or validating a multivariable prediction model for diagnosis or prognosis* (Continued)}

Results

Participants

$13 a \quad D ; V$

$13 b \quad D ; V$

13c V

Model development

$14 b$

Model specification

$15 \mathrm{a}$

Model performance

$15 b \quad D$

Model updating

$16 \quad D ; V$

$17 \quad$ V

Discussion

Limitations

Interpretation

18

$D ; V$

19a V

19b DiV

Implications

20

$D, V$

\section{Other information}

Supplementary information $21 \quad \mathrm{D} \cdot \mathrm{V}$

Funding $22 \quad \mathrm{D} ; \mathrm{V}$
Describe the flow of participants through the study, including the number of participants with and without the outcome and, if applicable, a summary of the follow-up time. A diagram may be helpful.

Describe the characteristics of the participants (basic demographics, clinical features, available predictors), including the number of participants with missing data for predictors and outcome.

For validation, show a comparison with the development data of the distribution of important variables (demographics, predictors and outcome).

Specify the number of participants and outcome events in each analysis.

If done, report the unadjusted association between each candidate predictor and outcome.

Present the full prediction model to allow predictions for individuals (i.e., all regression coefficients, and model intercept or baseline survival at a given time point).

Explain how to use the prediction model.

Report performance measures (with $\mathrm{Cls}$ ) for the prediction model.

If done, report the results from any model updating (i.e., model specification, model performance).

Discuss any limitations of the study (such as nonrepresentative sample, few events per predictor, missing data).

For validation, discuss the results with reference to performance in the development data, and any other validation data.

Give an overall interpretation of the results, considering objectives, limitations, results from similar studies, and other relevant evidence.

Discuss the potential clinical use of the model and implications for future research.

Provide information about the availability of supplementary resources, such as study protocol, Web calculator, and data sets.

Give the source of funding and the role of the funders for the present study.

*Items relevant only to the development of a prediction model are denoted by $D$, items relating solely to a validation of a prediction model are denoted by $V$, and items relating to both are denoted $D ; V$. We recommend using the TRIPOD Checklist in conjunction with the TRIPOD explanation and elaboration document.

The items relate to the title and abstract (items 1 and 2), background and objectives (item 3), methods (items 4 through 12), results (items 13 through 17), discussion (items 18 through 20), and other information (items 21 and 22). The TRIPOD Statement covers studies that report solely development $[12,15]$, both development and external validation, and solely external validation (with or without updating), of a prediction model [14] (Figure 1). Therefore, some items are relevant only for studies reporting the development of a prediction model (items 10a, $10 \mathrm{~b}, 14$, and 15), and others apply only to studies reporting the (external) validation of a prediction model (items 10c, 10 e, 12, 13c, 17, and 19a). All other items are relevant to all types of prediction model development and validation studies. Items relevant only to the development of a prediction model are denoted by $D$, items relating solely to a validation of a prediction model are denoted by $V$, whereas items relating to both types of study are denoted $D ; V$.

The recommendations within TRIPOD are guidelines only for reporting research and do not prescribe how to develop or validate a prediction model. Furthermore, the checklist is not a quality assessment tool to gauge the quality of a multivariable prediction model.

An ever-increasing number of studies are evaluating the incremental value of specific predictors, beyond established predictors or even beyond existing prediction 
models [18,42].The reporting of these studies fits entirely within the remit of TRIPOD (see accompanying explanation and elaboration document [43].

\section{The TRIPOD explanation and elaboration document}

In addition to the TRIPOD Statement, we produced a supporting explanation and elaboration document [43] in a similar style to those for other reporting guidelines [47-49]. Each checklist item is explained and accompanied by examples of good reporting from published articles. In addition, because many such studies are methodologically weak, we also summarize the qualities of good (and the limitations of less good) studies, regardless of reporting [43]. A comprehensive evidence base from existing systematic reviews of prediction models was used to support and justify the rationale for including and illustrating each checklist item. The development of the explanation and elaboration document was completed after several faceto-face meetings, teleconferences, and iterations among the authors. Additional revisions were made after sharing the document with the whole TRIPOD group before final approval.

\section{Role of the funding source}

There was no explicit funding for the development of this checklist and guidance document. The consensus meeting in June 2011 was partially funded by a National Institute for Health Research Senior Investigator Award held by Dr. Altman, Cancer Research UK, and the Netherlands Organization for Scientific Research. Drs. Collins and Altman are funded in part by the Medical Research Council. Dr. Altman is a member of the Medical Research Council Prognosis Research Strategy (PROGRESS) Partnership. The funding sources had no role in the study design, data collection, analysis, preparation of the manuscript, or decision to submit the manuscript for publication.

\section{Discussion}

Many reviews have showed that the quality of reporting in published articles describing the development or validation of multivariable prediction models in medicine is poor [23-27,29]. In the absence of detailed and transparent reporting of the key study details, it is difficult for the scientific and health care community to objectively judge the strengths and weaknesses of a prediction model study [34,50,51]. The explicit aim of this checklist is to improve the quality of reporting of published prediction model studies. The TRIPOD guideline has been developed to support authors in writing reports describing the development, validation or updating of prediction models, aid editors and peer reviewers in reviewing manuscripts submitted for publication, and help readers in critically appraising published reports.
The TRIPOD Statement does not prescribe how studies developing, validating, or updating prediction models should be undertaken, nor should it be used as a tool for explicitly assessing quality or quantifying risk of bias in such studies [52]. There is, however, an implicit expectation that authors have an appropriate study design and conducted certain analyses to ensure all aspects of model development and validation are reported. The accompanying explanation and elaboration document describes aspects of good practice for such studies, as well as highlighting some inappropriate approaches that should be avoided [43].

TRIPOD encourages complete and transparent reporting reflecting study design and conduct. It is a minimum set of information that authors should report to inform the reader about how the study was carried out. We are not suggesting a standardized structure of reporting, rather that authors should ensure that they address all the checklist items somewhere in their article with sufficient detail and clarity.

We encourage researchers to develop a study protocol, especially for model development studies, and even register their study in registers that accommodate observational studies (such as ClinicalTrials.gov) [53,54]. The importance of also publishing protocols for developing or validating prediction models, certainly when conducting a prospective study, is slowly being acknowledged $[55,56]$. Authors can also include the study protocol when submitting their article for peer review, so that readers can know the rationale for including individuals into the study or whether all of the analyses were prespecified.

To help the editorial process; peer reviewers; and, ultimately, readers, we recommend submitting the checklist as an additional file with the report, indicating the pages where information for each item is reported. The TRIPOD reporting template for the checklist can be downloaded from [57].

Announcements and information relating to TRIPOD will be broadcast on the TRIPOD Twitter address (@TRIPODStatement). The Enhancing the QUAlity and Transparency Of health Research (EQUATOR) Network [58] will help disseminate and promote the TRIPOD Statement.

Methodological issues in developing, validating, and updating prediction models evolve. TRIPOD will be periodically reappraised, and if necessary modified to reflect comments, criticisms, and any new evidence. We therefore encourage readers to make suggestions for future updates so that ultimately, the quality of prediction model studies will improve.

\section{Appendix: Members of the TRIPOD Group}

Gary Collins (University of Oxford, Oxford, United Kingdom); Douglas Altman (University of Oxford, Oxford, United Kingdom); Karel Moons (University Medical Center Utrecht, Utrecht, the Netherlands); Johannes Reitsma (University 
Medical Center Utrecht, Utrecht, the Netherlands); Virginia Barbour (PLoS Medicine, United Kingdom and Australia); Nancy Cook (Division of Preventive Medicine, Brigham \& Women's Hospital, Boston, Massachusetts); Joris de Groot (University Medical Center Utrecht, Utrecht, the Netherlands); Trish Groves (BMJ, London, United Kingdom); Frank Harrell, Jr. (Vanderbilt University, Nashville, Tennessee); Harry Hemingway (University College London, London, United Kingdom); John Ioannidis (Stanford University, Stanford, California); Michael W. Kattan (Cleveland Clinic, Cleveland, Ohio); André Knottnerus (Maastricht University, Maastricht, the Netherlands, and Journal of Clinical Epidemiology); Petra Macaskill (University of Sydney, Sydney, Australia); Susan Mallett (University of Oxford, Oxford, United Kingdom); Cynthia Mulrow (Annals of Internal Medicine, American College of Physicians, Philadelphia, Pennsylvania); David Ransohoff (University of North Carolina at Chapel Hill, Chapel Hill, North Carolina); Richard Riley (University of Birmingham, Birmingham, United Kingdom); Peter Rothwell (University of Oxford, Oxford, United Kingdom); Patrick Royston (Medical Research Council Clinical Trials Unit at University College London, London, United Kingdom); Willi Sauerbrei (University of Freiburg, Freiburg, Germany); Ewout Steyerberg (University Medical Center Rotterdam, Rotterdam, the Netherlands); Ian Stiell (University of Ottawa, Ottawa, Ontario, Canada); Andrew Vickers (Memorial Sloan Kettering Cancer Center, New York).

\section{Competing interests}

Authors have disclosed no conflicts of interest. Forms can be viewed at www. acponline.org/authors/icmje/ConflictOflnterestForms.do?msNum=M14-0697.

\section{Authors' contributions}

Conception and design: GSC, JBR, DGA, KGMM. Analysis and interpretation of the data: GSC, DGA, KGMM. Drafting of the article: GSC, JBR, DGA, KGMM. Critical revision of the article for important intellectual content: GSC, JBR, DGA, KGMM. Final approval of the article: GSC, JBR, DGA, KGMM. Provision of study materials or patients: GSC, KGM. Statistical expertise: GSC, JBR, DGA, KGMM. Obtaining of funding: GSC, DGA, KGMM. Administrative, technical, or logistic support: GSC, KGMM. Collection and assembly of data: GSC, DGA, KGMM.

\section{Acknowledgements \\ For contributors to the TRIPOD Statement, see the Appendix (available at www.annals.org).}

\section{Grant Support}

There was no explicit funding for the development of this checklist and guidance document. The consensus meeting in June 2011 was partially funded by a National Institute for Health Research Senior Investigator Award held by Dr. Altman, Cancer Research UK (grant C5529), and the Netherlands Organization for Scientific Research (ZONMW 918.10.615 and 91208004). Drs. Collins and Altman are funded in part by the Medical Research Council (grant G1100513). Dr. Altman is a member of the Medical Research Council Prognosis Research Strategy (PROGRESS) Partnership (G0902393/99558).

\section{Requests for Single Reprints}

Gary S. Collins, PhD, Centre for Statistics in Medicine, Nuffield Department of Orthopaedics, Rheumatology and Musculoskeletal Sciences, Botnar Research Centre, University of Oxford, Oxford OX3 7LD, United Kingdom; e-mail, gary. collins@csm.ox.ac.uk

\section{Author details}

${ }^{1}$ Nuffield Department of Orthopaedics, Rheumatology and Musculoskeletal Sciences, Botnar Research Centre, Centre for Statistics in Medicine, University of Oxford, Oxford OX3 7LD, UK. ${ }^{2}$ Julius Center for Health Sciences and Primary Care, University Medical Center Utrecht, PO Box 85500, 3508 GA, Utrecht, the Netherlands.

Received: 13 November 2014 Accepted: 14 November 2014

Published online: 06 January 2015

\section{References}

1. Moons KG, Royston P, Vergouwe Y, Grobbee DE, Altman DG: Prognosis and prognostic research: what, why, and how? BMJ 2009, 338:b375. PMID: 19237405.

2. Steyerberg EW: Clinical Prediction Models: A Practical Approach to Development, Validation, and Updating. New York: Springer; 2009.

3. Dorresteijn JA, Visseren FL, Ridker PM, Wassink AM, Paynter NP, Steyerberg EW, van der Graaf Y, Cook NR: Estimating treatment effects for individual patients based on the results of randomised clinical trials. BMJ 2011 343:d5888. PMID: 21968126.

4. Hayward RA, Kent DM, Vijan S, Hofer TP: Multivariable risk prediction can greatly enhance the statistical power of clinical trial subgroup analysis. BMC Med Res Methodol 2006, 6:18. PMID: 16613605.

5. Riley RD, Hayden JA, Steyerberg EW, Moons KG, Abrams K, Kyzas PA, Malats N, Briggs A, Schroter S, Altman DG, Hemingway H: Prognosis Research Strategy (PROGRESS) 2: prognostic factor research. PLOS Med 2013, 10:e1001380. PMID: 23393429.

6. Steyerberg EW, Moons KG, van der Windt DA, Hayden JA, Perel P, Schroter S, Riley RD, Hemingway H, Altman DG: Prognosis Research Strategy (PROGRESS) 3: prognostic model research. PLOS Med 2013, 10:e1001381. PMID: 23393430.

7. Anderson KM, Odell PM, Wilson PW, Kannel WB: Cardiovascular disease risk profiles. Am Heart J 1991, 121:293-298. PMID: 1985385.

8. Stiell IG, Greenberg GH, MCKnight RD, Nair RC, McDowell I, Worthington JR: A study to develop clinical decision rules for the use of radiography in acute ankle injuries. Ann Emerg Med 1992, 21:384-390. PMID: 1554175.

9. Nashef SA, Roques F, Michel P, Gauducheau E, Lemeshow S, Salamon R: European system for cardiac operative risk evaluation (EuroSCORE). Eur J Cardiothorac Surg 1999, 16:9-13. PMID: 10456395.

10. Haybittle JL, Blamey RW, Elston CW, Johnson J, Doyle PJ, Campbell FC, Nicholson Rl, Griffiths K: A prognostic index in primary breast cancer. Br J Cancer 1982, 45:361-366. PMID: 7073932.

11. Le Gall JR, Loirat P, Alperovitch A, Glaser P, Granthil C, Mathueu D, Mercier $P$, Thomas R, Villers D: A simplified acute physiology score for ICU patients. Crit Care Med 1984, 12:975-977. PMID: 6499483.

12. Royston P, Moons KG, Altman DG, Vergouwe Y: Prognosis and prognostic research: developing a prognostic model. BMJ 2009, 338:b604. PMID 19336487.

13. Moons KG, Kengne AP, Grobbee DE, Royston P, Vergouwe Y, Altman DG, Woodward M: Risk prediction models: Il. External validation, model updating, and impact assessment. Heart 2012, 98:691-698. PMID: 22397946.

14. Altman DG, Vergouwe $Y$, Royston P, Moons KG: Prognosis and prognostic research: validating a prognostic model. BMJ 2009, 338:b605. PMID: 19477892

15. Moons KG, Kengne AP, Woodward M, Royston P, Vergouwe Y, Altman DG, Grobbee DE: Risk prediction models: I. Development, internal validation, and assessing the incremental value of a new (bio)marker. Heart 2012, 98:683-690. PMID: 22397945.

16. Steyerberg EW, Harrell FE, Borsboom GJJM, Eijkemans MJC, Vergouwe Y, Habbema JDF: Internal validation of predictive models: efficiency of some procedures for logistic regression analysis. J Clin Epidemiol 2001, 54:774-781. PMID: 11470385.

17. Justice AC, Covinsky KE, Berlin JA: Assessing the generalizability of prognostic information. Ann Intern Med 1999, 130:515-524. PMID: 10075620

18. Steyerberg EW, Pencina MJ, Lingsma HF, Kattan MW, Vickers AJ, Van Calster B: Assessing the incremental value of diagnostic and prognostic markers: a review and illustration. Eur J Clin Invest 2012, 42:216-228. PMID: 21726217.

19. Steyerberg EW, Bleeker SE, Moll HA, Grobbee DE, Moons KG: Internal and external validation of predictive models: a simulation study of bias and precision in small samples. J Clin Epidemiol 2003, 56:441-447. PMID: 12812818 
20. Steyerberg EW, Eijkemans MJ, Habbema JD: Application of shrinkage techniques in logistic regression analysis: a case study. Statistica Neerlandica 2001, 55:76-88.

21. Reilly BM, Evans AT: Translating clinical research into clinical practice: impact of using prediction rules to make decisions. Ann Intern Med 2006, 144:201-209. PMID: 16461965.

22. Wallace E, Smith SM, Perera-Salazar R, Vaucher P, McCowan C, Collins G, Verbakel J, Lakhanpaul M, Fahey T: Framework for the impact analysis and implementation of clinical prediction rules (CPRs). BMC Med Inform Decis Mak 2011, 11:62. PMID: 21999201.

23. Bouwmeester W, Zuithoff NP, Mallett S, Geerlings MI, Vergouwe Y, Steyerberg EW, Altman DG, Moons KG: Reporting and methods in clinical prediction research: a systematic review. PLoS Med 2012, 9:1-12. PMID: 22629234.

24. Collins GS, Mallett S, Omar O, Yu LM: Developing risk prediction models for type 2 diabetes: a systematic review of methodology and reporting. BMC Med 2011, 9:103. PMID: 21902820.

25. Collins GS, Omar O, Shanyinde M, Yu LM: A systematic review finds prediction models for chronic kidney were poorly reported and often developed using inappropriate methods. J Clin Epidemio/ 2013, 66:268-277. PMID: 23116690.

26. Mallett S, Royston P, Dutton S, Waters R, Altman DG: Reporting methods in studies developing prognostic models in cancer: a review. BMC Med 2010, 8:20. PMID: 20353578.

27. Laupacis A, Sekar N, Stiell IG: Clinical prediction rules. A review and suggested modifications of methodological standards. JAMA 1997, 277:488-494. PMID: 9020274

28. Collins GS, de Groot JA, Dutton S, Omar O, Shanyinde M, Tajar A, Voysey M, Wharton R, Yu LM, Moons KG, Altman DG: External validation of multivariable prediction models: a systematic review of methodological conduct and reporting. BMC Med Res Methodol 2014, 14:40. PMID: 24645774

29. Ettema RG, Peelen LM, Schuurmans MJ, Nierich AP, Kalkman CJ, Moons KG: Prediction models for prolonged intensive care unit stay after cardiac surgery: systematic review and validation study. Circulation 2010, 122:682-689. PMID: 20679549.

30. Goff DC, Lloyd-Jones DM, Bennett G, Coady S, D'Agostino RB, Gibbons R, Greenland P, Lackland DT, Levy D, O'Donnell CJ, Robinson JG, Schwartz JS, Shero ST, Smith SC Jr, Sorlie P, Stone NJ, Wilson PW, Jordan HS, Nevo L, Wnek J, Anderson JL, Halperin JL, Albert NM, Bozkurt B, Brindis RG, Curtis LH, DeMets D, Hochman JS, Kovacs RJ, Ohman EM, et al: 2013 ACC/AHA guideline on the assessment of cardiovascular risk: a report of the American College of Cardiology/American Heart Association Task Force on Practice Guidelines. Circulation 2014, 129:S49-S73. PMID: 24222018.

31. Rabar S, Lau R, O'Flynn N, Li L, Barry P, Guideline Development Group: Risk assessment of fragility fractures: summary of NICE guidance. BMJ 2012, 345:e3698. PMID: 22875946.

32. Laine C, Goodman SN, Griswold ME, Sox HC: Reproducible research: moving toward research the public can really trust. Ann Intern Med 2007, 146:450-453. PMID: 17339612.

33. Siontis GC, Tzoulaki I, Siontis KC, loannidis JP: Comparisons of established risk prediction models for cardiovascular disease: systematic review. BMJ 2012, 344:e3318. PMID: 22628003

34. Seel RT, Steyerberg EW, Malec JF, Sherer M, Macciocchi SN: Developing and evaluating prediction models in rehabilitation populations. Arch Phys Med Rehabil 2012, 93:S138-S153. PMID: 22840880

35. Collins GS, Moons KG: Comparing risk prediction models. BMJ 2012, 344:e3186. PMID: 22628131.

36. Knottnerus JA: Diagnostic prediction rules: principles, requirements and pitfalls. Prim Care 1995, 22:341-363. PMID: 7617791.

37. McShane LM, Altman DG, Sauerbrei W, Taube SE, Gion M, Clark GM, Statistics Subcommittee of the NCI-EORTC Working Group on Cancer Diagnostics: Reporting recommendations for tumor marker prognostic studies (REMARK). J Natl Cancer Inst 2005, 97:1180-1184. PMID: 16106022

38. Moons KG, Altman DG, Vergouwe Y, Royston P: Prognosis and prognostic research: application and impact of prognostic models in clinical practice. BMJ 2009, 338:b606. PMID: 19502216

39. von Elm E, Altman DG, Egger M, Pocock SJ, Gøtzsche PC, Vandenbroucke JP, STROBE Initiative: Strengthening the Reporting of Observational Studies in Epidemiology (STROBE) statement: guidelines for reporting observational studies. BMJ 2007, 335:806-808. PMID: 17947786.
40. Bossuyt PM, Reitsma JB, Bruns DE, Gatsonis CA, Glasziou PP, Irwig LM, Lijmer JG, Moher D, Rennie D, de Vet HC: Towards complete and accurate reporting of studies of diagnostic accuracy: the STARD Initiative. Radiology 2003, 226:24-28. PMID: 12511664.

41. Janssens AC, loannidis JP, van Duijn CM, Little J, Khoury MJ, GRIPS Group: Strengthening the reporting of genetic risk prediction studies: the GRIPS statement. Eur J Clin Invest 2011, 41:1004-1009. PMID: 21434891.

42. Tzoulaki I, Liberopoulos G, loannidis JP: Use of reclassification for assessment of improved prediction: an empirical evaluation. Int $J$ Epidemiol 2011, 40:1094-1105. PMID: 21325392.

43. Moons KGM, Altman DG, Reitsma JB, loannidis JPA, Macaskill P, Steyerberg EW, Vickers AJ, Ransohoff DF, Collins GS: Transparent Reporting of a multivariable prediction model for Individual Prognosis Or Diagnosis (TRIPOD): explanation and elaboration. Ann Intern Med 2015, 162:W1-W73.

44. Moher D, Schulz KF, Simera I, Altman DG: Guidance for developers of health research reporting guidelines. PLoS Med 2010, 16:e1000217. PMID: 20169112

45. Little J, Higgins JP, loannidis JP, Moher D, Gagnon F, von Elm E, Khoury MJ, Cohen B, Davey-Smith G, Grimshaw J, Scheet P, Gwinn M, Williamson RE, Zou GY, Hutchings K, Johnson CY, Tait V, Wiens M, Golding J, van Duijn C, McLaughlin J, Paterson A, Wells G, Fortier I, Freedman M, Zecevic M, King R, Infante-Rivard C, Stewart A, Birkett N: STrengthening the REporting of Genetic Association Studies (STREGA): an extension of the STROBE statement. PLoS Med 2009, 6:e22. PMID: 19192942.

46. Moher D, Liberati A, Tetzlaff J, Altman DG, PRISMA Group: Preferred reporting items for systematic reviews and meta-analyses: the PRISMA statement. Ann Intern Med 2009, 151:264-269. PMID: 19622511.

47. Janssens AC, loannidis JP, Bedrosian S, Boffetta P, Dolan SM, Dowling N, Fortier I, Freedman AN, Grimshaw JM, Gulcher J, Gwinn M, Hlatky MA, Janes H, Kraft P, Melillo S, O'Donnell CJ, Pencina MJ, Ransohoff D, Schully SD, Seminara D, Winn DM, Wright CF, van Duijn CM, Little J, Khoury MJ: Strengthening the reporting of genetic risk prediction studies (GRIPS): explanation and elaboration. Eur J Clin Invest 2011, 41:1010-1035. PMID: 21434890.

48. Altman DG, McShane LM, Sauerbrei W, Taube SE: Reporting recommendations for tumor marker prognostic studies (REMARK): explanation and elaboration. BMC Med 2012, 10:51. PMID: 22642691.

49. Vandenbroucke JP, von Elm E, Altman DG, Gøtzsche PC, Mulrow CD, Pocock SJ, Poole C, Schlesselman JJ, Egger M: Strengthening the Reporting of Observational Studies in Epidemiology (STROBE): explanation and elaboration. Epidemiology 2007, 18:805-835. PMID: 18049195.

50. Collins GS, Michaëlsson K: Fracture risk assessment: state of the art, methodologically unsound, or poorly reported? Curr Osteoporos Rep 2012, 10:199-207. PMID: 22688862.

51. Järvinen TL, Jokihaara J, Guy P, Alonso-Coello P, Collins GS, Michaëlsson K, Sievänen H: Conflicts at the heart of the FRAX tool. CMAJ 2014, 186:165-167. PMID: 24366895.

52. Moons KG, de Groot JA, Bouwmeester W, Vergouwe Y, Mallett S, Altman DG, Reitsma JB, Collins GS: Critical appraisal and data extraction for the systematic reviews of prediction modelling studies: the CHARMS checklist. PLoS Med 2014, 11:e1001744. PMID: 25314315.

53. Williams RJ, Tse T, Harlan WR, Zarin DA: Registration of observational studies: is it time? CMAJ 2010, 182:1638-1642. PMID: 20643833

54. Hemingway $H$, Riley RD, Altman DG: Ten steps towards improving prognosis research. BMJ 2009, 339:b4184. PMID: 20042483.

55. Canadian CT Head and C-Spine (CCC) Study Group: Canadian C-Spine Rule study for alert and stable trauma patients: I. Background and rationale. CJEM 2002, 4:84-90. PMID: 17612425.

56. Canadian CT Head and C-Spine (CCC) Study Group: Canadian C-Spine Rule study for alert and stable trauma patients: II. Study objectives and methodology. CJEM 2002, 4:185-193. PMID: 17609004.

57. TRIPOD. www.tripod-statement.org

58. EQUATOR. www.equator-network.org 